\title{
Standar Pengukuran Debit dan Tekanan Air Pada Mesin Uji Pompa Sentrifugal Dengan Menggunakan Inverter
}

\author{
Budhy Basuki \\ Badan Standardisasi Nasional, Kawasan Puspiptek Serpong Tangerang \\ E-mail: budhybasuki@gmail.com
}

Received:11 September 2021

Revision :2 Oktober 2021

Accepted: 10 November 2021

\begin{abstract}
Abstrak: Standar untuk mesin uji pompa sentrifugal telah dibuat dengan model seri dan paralel. Pengukuran yang dilakukan adalah tekanan dan debit air yang dihasilkan oleh sebuah pompa. Putaran pompa dapat divariasikan dengan sebuah inverter dan inverter dapat dihubungkan dengan dua buah pompa. Hasil pengujian Frekwensi $50 \mathrm{~Hz}$ pada pengujian pompa seri arus pompa-1 dan pompa-2 masing 1,75 amper dan 1,8 amper dan pengujian pompa paralel $50 \mathrm{~Hz}$ pompa 1 dan pompa 2 didapat 1,8 dan 1,81 amper.
\end{abstract}

Kata Kunci: sentrifugal, model serie dan paralel, tekanan dan debit, inverter

Abstract: The machine centrifugal pump testing have been made with series and parallel type. Measurement carry out is pressure and air flow capacity pump. The pump can be variable with a inveter and one inveter connected with two pump. The result testing frequency $50 \mathrm{~Hz}$ of pumps testing series and pump-1 dan pump -2 is 1,75 ampere dan 1,8 ampere and parallel testing pump $50 \mathrm{~Hz}$ pump-1 and pump-2 is 1,8 and 1,81 ampere.

Keywords: centrifugal, series and parallel models, pressure and discharge, inverter

\section{PENDAHULUAN}

Pompa adalah mesin konversi energi yang merubah tenaga listrik ke mekanik menjadi tekanan atau energi kinetik [1]. Tekanan Pompa dapat diatur putarannya dengan menggunakan inverter. Telah dibuat sebuah sistem pengujian pompa sentrifugal seri dan paralel inverter dapat dipasang untuk mengatur putaran dua buah pompa dengan satu inverter. Standar yang berhubungan dengan pemilihan dan instalasi pompa sentrifugal [2].

Fungsi pompa sangat penting untuk memindahkan cairan dari sumur ke tangki penyimpanan sebagai alat bantu pekerjaan manusia. Persyaratan standar diperlukan untuk mengetahui kapasitas pompa, maka terlebih dahulu harus diketahui kemampuan aliran pompa dan dari head pompa yang diperlukan untuk memindahkan cairan yang akan dipompa. Agar pompa tidak terjadi kavitasi perlu estimasi berapa tekanan minimum yang ada di pompa. Kemampuan pompa menunjukkan jumlah debit yang dikeluarkan berapa m3/jam. Kapasitas pompa perlu diketahui minimum dan maksimumnya dan juga perlu mengetahui kemampuan pengisapan dan pengeluaran [3].

Menurut proses perpindahan energi dan fluida cair sebagai bahan aliran maka pompa sentrifugal termasuk mesin aliran fluida hidrolik. Cairan masuk secara aksial melalui mata casing, terperangkap di bilah impeller, dan diputar secara tangensial dan radial ke luar sampai keluar melalui semua bagian melingkar dari impeller ke bagian diffuser dari casing. Fluida memperoleh kecepatan dan tekanan saat melewati baling-baling. Diffuser berbentuk donat, atau gulir, bagian casing memperlambat kecepatan mengalir dan selanjutnya meningkatkan tekanan [4].

Hal ini bisa diketahui dari proses perpindahan tenaga di dalam impeller akibat dari pembelokan arus aliran fluida. Tinggi kenaikan dari pompa sentrifugal adalah sama dengan perbandingan kuadrat dari kecepatan sedemikian rupa sehingga fluida tersebut mempunyai kecepatan mengalir keluar dari impeller. Karakteristik 
pompa sentrifugal ditentukan oleh besaran-besaran; volume fluida yang dipompa, head, daya yang dibutuhkan untuk menggerakkan pompa, kecepatan putar, effisiensi, alat atau keadaan di sisi bagian seksi isap. Fluida masuk melalui saluran isap dan kemudian dalam arah aksial mengalir ke bagian punggung impeller yang melengkung. Karena adanya sentrifugal yang ada pada saluran impeller tersebut maka fluida menjadi bergerak terdorong keluar. Distribusi fluida karakteristik statis berpengaruh pada permukaan benda padat terapung dan terendam, ketika kecepatan fluida nol diasumsikan kondisi hidrostatis dengan tekanan bervariasi dari berat fluida [5].

Asumsi tersebut fluida diketahui dari medan grafitasi maka tekanan dapat dihitung dan diintegrasikan [6]. Pada penelitian ini memiliki adalah untuk mengetahui tentang karakteristik dua buah pompa yang dipasang dengan menggunakan satu inverter. Dimana pengukuran yang dilakukan adalah tegangan, arus pompa, tekanan masuk, keluar pompa dan debit air.

\section{METODOLOGI}

Sistem instalasi pengujian pompa sentrifugal terlihat seperti gambar berikut :

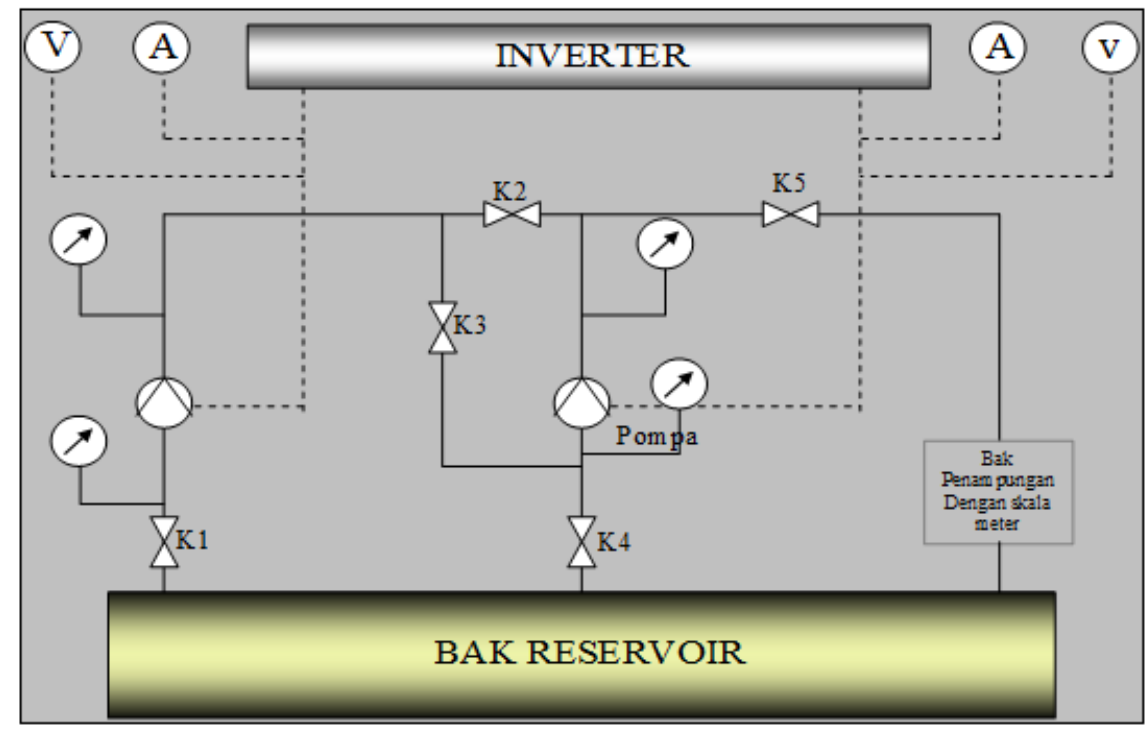

Gambar 1. Sistem pengujian pompa

\section{A. Pengujian Metode Seri}

1. Hubungkan kabel listrik masukan dari system dengan sumber listrik panas.

2. Tekan tombol ON pada panel instrumen yang telah ditentukan.

3. Tekan tombol frekwensi untuk mengatur freqkwensi yang dikehendaki.

4. Amati putaran pompa dengan menggunakan tachometer.

5. Buka katup K1 dan K3.

6. Tutup katup K2 dan katup K4.

7. Buka katup K5 untuk membuka aliran fluida keluar menuju skala weirmeter.

\section{B. Pengujian Metode Seri}

1. Hubungkan kabel listrik masukan dari system dengan sumber listrik panas.

2. Tekan tombol ON pada panel instrumen.

3. Tekan tombol frekwensi untuk mengatur freqkwensi yang dikehendaki.

4. Amati putaran pompa dengan menggunakan tachometer.

5. Buka katup K1 dan K2.

6. Tutup katup K3.

7. Buka katup K4 dan katup K5 untuk membuka aliran fluida keluar menuju skala weirmeter 


\section{Parameter Pengujian}

Head pompa adalah energi yang diberikan pompa pada ketinggian tekanan antara muka air sisi masuk dan sisi kelaur. Head pompa dinyatakan dengan persamaan:

$H=\frac{P_{2}-P_{1}}{\rho \cdot g}$

Pada kasus tertentu, head pompa adalah selisih penjumlahan aljabar antara head seksi keluar (tekanan) dan head seksi isap (masuk) dan dinyatakan dengan persamaan:

$H=H_{\text {tekan }}-H_{\text {isap }}$

dengan:

$$
\begin{aligned}
H & =H_{\text {statis }}+H_{\text {isap }} \\
& =\frac{P}{\rho \cdot g}+\frac{V^{2}}{2 \cdot g}
\end{aligned}
$$

Sedangkan V $=$ kecepatan aliran: $\frac{Q}{A}$

Daya hidrolik adalah daya pemompaan dari pompa sentrifugal yang bisa digunakan dan dipindahkan ke fluida. Daya hidrolik dinyatakan dengan persamaan:

$N_{h}=\rho \cdot g \cdot Q \cdot H$

Daya poros yang diukur untuk pompa sentrifugal diamati dengan memasukkan unsur tegangan dan arus motor penggerak. Daya ini dinyatakan dengan persamaan :

$N_{p}=V \cdot A \cdot \operatorname{Cos} \varphi$

Efisiensi pompa didefinisikan perbandingan antara daya masukan (daya poros) dengan daya keluaran (daya hidrolik). Effisiensi pompa dinyatakan dengan persamaan:

$\eta_{p}=\frac{N_{h}}{N_{p}} \times 100 \%$

Perhitungan kecepatan spesifik pompa diberikan oleh persamaan berikut:

$N_{s}=\frac{\eta \times Q^{1 / 2}}{H^{3 / 4}}$

Besarnya debit pompa dalam pengujian ini adalah dengan menggunakan skala weirmeter atau takik segitiga, sistem ini sangat tepat bila dikaitkan dengan penggunaan debit yang cukup kecil dengan kontraksi luapan cairan diabaikan. Cairan yang tertampung / menggenang di dalam bak penampung (flow regulation suction) bergerak menuju sekat ukur. Dengan mengukur ketinggian permukaan cairan kita dapat menentukan laju aliran, sekat (weir) yang terbuat dari lembaran baja memungkinkan cairan mengalir di atas permukaan meloncat bebas.

Konstruksi sekat ukur segitiga terdiri dari:

- Pelat sekat ukur

- Penahan sekat ukur (supported plate)

- Saluran (chane) 
Saluran terbagi atas 6 (enam) bagian yaitu:

- Bagian asal aliran (griwing section)

- Bagian pengarah aliran (flow straghting section)

- Bagian aliran terarah (flow regulation section)

- Bagian penampang aliran (flow containing section)

\section{HASIL DAN PEMBAHASAN}

Pengujian yang telah dilakukan dapat dihasilkan pada tabel dibawah ini.

Tabel 1. Hasil Data Pengujian Seri

\begin{tabular}{|c|c|c|c|c|c|c|c|c|c|}
\hline \multirow[t]{2}{*}{$\begin{array}{l}\text { Frekuensi } \\
\quad(\mathrm{Hz})\end{array}$} & \multicolumn{2}{|c|}{$\begin{array}{c}\text { Tekanan } \\
\text { Seksi Isap } \\
\text { (Bar) } \\
\end{array}$} & \multicolumn{2}{|c|}{$\begin{array}{c}\text { Tekanan } \\
\text { Seksi Tekan } \\
\text { (Bar) }\end{array}$} & \multirow{2}{*}{$\begin{array}{c}\text { Tinggi } \\
\text { Weirmeter } \\
(\mathbf{c m})\end{array}$} & \multicolumn{2}{|c|}{$\begin{array}{l}\text { Ammeter } \\
\text { (A) }\end{array}$} & \multicolumn{2}{|c|}{$\begin{array}{c}\text { Voltmeter } \\
\text { (Volt) }\end{array}$} \\
\hline & $\mathrm{P}-1$ & $\mathrm{P}-2$ & $\mathrm{P}-1$ & $\mathrm{P}-2$ & & $\mathrm{P}-1$ & $\mathrm{P}-2$ & $\mathrm{P}-1$ & $\mathrm{P}-2$ \\
\hline 20 & $-0,3$ & $-0,21$ & 0 & 0 & 6,5 & 1,4 & 1,6 & 125 & 125 \\
\hline 30 & $-0,38$ & $-0,32$ & 0 & 0 & 6,4 & 1,25 & 1,25 & 150 & 150 \\
\hline 40 & $-0,38$ & $-0,22$ & 0 & 0 & 6,4 & 1,25 & 1,25 & 175 & 175 \\
\hline 50 & 0,42 & 0,42 & 0 & 0 & 6,5 & 1,27 & 1,75 & 220 & 220 \\
\hline
\end{tabular}

Tabel 2. Hasil Data Pengujian Seri

\begin{tabular}{|c|c|c|c|c|c|c|c|c|c|}
\hline \multirow[t]{2}{*}{$\begin{array}{l}\text { Frekuensi } \\
\qquad(\mathbf{H z})\end{array}$} & \multicolumn{2}{|c|}{$\begin{array}{c}\text { Tekanan } \\
\text { Seksi Isap } \\
\text { (Bar) }\end{array}$} & \multicolumn{2}{|c|}{$\begin{array}{c}\text { Tekanan } \\
\text { Seksi Tekan } \\
\text { (Bar) }\end{array}$} & \multirow{2}{*}{$\begin{array}{c}\text { Tinggi } \\
\text { Weirmeter } \\
(\mathbf{c m})\end{array}$} & \multicolumn{2}{|c|}{$\begin{array}{l}\text { Ammeter } \\
\text { (A) }\end{array}$} & \multicolumn{2}{|c|}{$\begin{array}{l}\text { Voltmeter } \\
\text { (Volt) }\end{array}$} \\
\hline & $\mathrm{P}-1$ & $\mathrm{P}-2$ & $\mathrm{P}-1$ & $\mathrm{P}-2$ & & P-1 & P-2 & P-1 & P-2 \\
\hline 20 & $-0,3$ & $-0,4$ & 0,8 & 0 & 7,6 & 1,4 & 1,6 & 125 & 125 \\
\hline 30 & $-0,29$ & $-0,52$ & 0,9 & 0,5 & 7,9 & 1,4 & 1,6 & 150 & 150 \\
\hline 40 & $-0,3$ & $-0,6$ & 0,1 & 0,5 & 8,1 & 1,4 & 1,6 & 175 & 175 \\
\hline 50 & 0,3 & 0,68 & 0,12 & 0,8 & 8,2 & 1,8 & 1,81 & 220 & 220 \\
\hline
\end{tabular}

Tabel 3. Hasil Data Perhitungan Pengujian Serie

\begin{tabular}{cccccc}
\hline Frekuensi & $\mathbf{Q}\left(\mathbf{M}^{\mathbf{3}} / \mathbf{s}\right)$ & $\mathbf{H}(\mathbf{m})$ & $\mathbf{N}_{\mathbf{h}}($ watt $)$ & $\mathbf{N}_{\mathbf{p}}($ watt $)$ & $\boldsymbol{\eta}_{\mathbf{p}}(\boldsymbol{\%})$ \\
\hline 20 & 0,0015 & 5,2 & 76,5 & 600 & 12,8 \\
30 & 0,0014 & 7,13 & 97,9 & 684 & 14,3 \\
$\mathbf{4 0}$ & $\mathbf{0 , 0 0 1}$ & $\mathbf{6 , 1}$ & $\mathbf{5 9 , 8 4}$ & $\mathbf{7 4 2}$ & $\mathbf{8}$ \\
50 & 0,002 & 8,6 & 168,7 & 1249,6 & 13,5 \\
\hline
\end{tabular}

Tabel 4. Hasil Data Perhitungan Pengujian Paralel

\begin{tabular}{cccccc}
\hline Frekuensi & $\mathbf{Q}\left(\mathbf{M}^{\mathbf{3}} / \mathbf{s}\right)$ & $\mathbf{H}(\mathbf{m})$ & $\mathbf{N}_{\mathbf{h}}$ (watt) & $\mathbf{N}_{\mathbf{p}}$ (watt) & $\boldsymbol{\eta}_{\mathbf{p}}(\boldsymbol{\%})$ \\
\hline 20 & 0,0022 & 15,3 & 330 & 600 & 55 \\
30 & 0,0024 & 23,4 & 550,9 & 720 & 76,5 \\
40 & 0,0026 & 14,9 & 406 & 840 & 48,3 \\
50 & 0,0027 & 19,4 & 514 & 1271 & 40,4 \\
\hline
\end{tabular}


58 | Budhy Basuki, Standar Pengukuran Debit dan Tekanan Air Pada Mesin Uji Pompa Sentrifugal ....,

Dari tabel-1 dan tabel-2 dapat dilihat dengan frekwensi inverter $20 \mathbf{~ H Z}$ didapat arus pada pompa 1 dapat 1,4 amper dan pompa 2 dapat 1,6 amper. Frekwensi $50 \mathrm{~Hz}$ pada pengujian pompa seri arus pompa -1 dan pompa -2 masing 1,75 amper dan 1,8 amper dan pengujian pompa paralel $\mathbf{5 0} \mathbf{~ H z}$ pompa 1 dan pompa 2 didapat 1,8 amper dan 1,81 amper. Sedangkan tegangan baik pengujian pompa seri dan paralel pada $20 \mathrm{~Hz}$ adalah 1,2 volt pada $20 \mathrm{~Hz}$ sedangkan $50 \mathrm{~Hz}$ tegangan 220 volt. Disini terjadi perbedaan walaupun pompanya sama kapasitas hal ini disebabkan karena gulungan dan diameter tembaga.

\section{KESIMPULAN}

Dari hasil pengujian dapat disimpulkan bahwa menggunakan 1 inverter yang dihubungkan dengan 2 buah pompa menghasilkan pengujian pompa seri dengan frekwensi $20 \mathrm{~Hz}$ diperoleh arus pompa 1 dan pompa 2 masing-masimg 1,4 dan 1,6 amper dan tegangannya 125 dan 125 volt demikin juga pada pengujian pompa paralel. Frekwensi $50 \mathrm{~Hz}$ pada pengujian pompa seri arus pompa-1 dan pompa-2 masing 1,75 amper dan 1,8 amper dan pengujian pompa paralel $50 \mathrm{~Hz}$ pompa 1 dan pompa 2 didapat 1,8 amper dan 1,81 amper. Sedangkan tegangan baik pengujian pompa seri dan paralel pada $20 \mathrm{~Hz}$ adalah 1,2 volt pada $20 \mathrm{~Hz}$ sedangkan $50 \mathrm{~Hz}$ tegangan 220 volt.

\section{DAFTAR PUSTAKA}

[1] F. Dietzel, Turbin Pompa dan Kompresor Edisi 5. Jakarta: Erlangga, 1996.

[2] Badan Standardisasi Nasional, "SNI 0141.1-2008 Pompa air sentrifugal untuk irigasi -Prosedur dan cara uji." 2008.

[3] S. A. Darmawan, "Pompa Sentrifugal," Universitas Sebelas Maret 1.pp. 1-34, 2016.

[4] F. M. White, Fluid Mechanics Seventh Edition. Boston: McGraw-Hill, 1991.

[5] A. C. Srivastava and Sutanto, Teknik Instrumentasi. Jakarta: Universitas Indonesia (UI-Press), 2006.

[6] F. M. White, Fluid Mechanics Fourth Edition. Boston: McGraw-Hill, 1999. 